\title{
Variabilidade temporal e espacial da precisão das estimativas de elementos meteorológicos no Rio Grande do Sul
}

\author{
Spatial and temporal variability of estimate precision in meteorological elements at \\ Rio Grande do Sul Brazil
}

\author{
Alberto Cargnelutti Filho ${ }^{I}$ Ronaldo Matzenauer ${ }^{I I}$ Jaime Ricardo Tavares Maluf ${ }^{\text {II }}$ \\ Bernadete Radin ${ }^{\text {II }}$
}

\section{RESUMO}

O planejamento de atividades agropecuárias exige que os riscos climáticos, em um determinado local e período do ano, sejam estimados com máxima precisão. Dessa forma, foram utilizados os dados de 15 locais do Estado do Rio Grande do Sul, com o objetivo de estudar a variabilidade temporal e espacial da precisão das estimativas das médias mensais de precipitação pluvial, insolação, radiação solar global $e$ temperaturas mínima, média e máxima. Para isso, calculouse o erro de estimação (semiamplitude do intervalo de confiança) (EE), em percentagem da estimativa da média mensal de precipitação pluvial, insolação, radiação solar global e temperaturas mínima, média e máxima, para cada mês e local, que foi utilizado como medida de precisão. A partir do EE, para cada um dos elementos meteorológicos, agruparam-se os meses e os locais, por meio do método hierárquico de Ward, e calculou-se o coeficiente de correlação linear de Pearson entre as matrizes de distância euclidiana média padronizada e gráfica a fim de verificar a consistência dos agrupamentos. Conclui-se que a precisão das estimativas, média de meses e locais, entre os elementos meteorológicos, aumenta na seguinte ordem: precipitação pluvial ( $E E=21,66 \%)$, insolação ( $E E=6,74 \%)$, radiação solar global $(E E=5,52 \%)$ e temperaturas mínima $(E E=4,40 \%)$, média $(E E=2,63 \%)$ e máxima $(E E=2,27 \%)$. Há variabilidade da precisão das estimativas das médias mensais de precipitação pluvial, insolação, radiação solar global e temperaturas mínima, média e máxima, no Estado do Rio Grande do Sul, no tempo (meses) e no espaço (locais). Estimativas com base em 30 anos de observações têm precisão menor nos meses de abril, maio, junho, julho, agosto e setembro, em relação aos demais meses.

Palavras-chave: série temporal, amostragem, erro de estimação, intervalo de confiança, estatística inferencial.

\begin{abstract}
Planning agricultural activities requires that climatic risks in each location and time of year are estimated with maximum precision. In this estudy data from15 locations of Rio Grande do Sul, Brazil, were used with the objective of studing spatial and temporal variability of the precision estimates average of monthly rainfall, sunshine, solar radiation global and temperatures minimum, mean and maximum. It was estimated the estimation error (half-amplitude of the confidence interval) (EE) in percentage of estimate average monthly rainfall, sunshine, solar radiation global and temperatures minimum, mean and maximum for each month and location, which was used as a measure of precision. From the EE, for each meteorological elements, months and locations were clustered by hierarchical method of Ward. The Pearson's linear correlation coefficient between the arrays of the standardized average euclidian distance and graphics was calculated in order to check the clusters consistency. It was concluded that the precision estimates, average of months and locations, between the meteorological elements, increases in the following order: rainfall ( $E E=21.66 \%)$, sunshine ( $E E=6.74 \%)$, global solar radiation $(E E=5.52 \%)$ and temperatures minimum $(E E=4.40 \%)$, mean $(E E=2.63 \%)$ and maximum $(E E=2.27 \%)$. Results showed that there is variability in precision estimate of monthly average rainfall, sunshine, global solar radiation and minimum, mean and maximum temperatures in Rio Grande do Sul, both in temporal and spatial scale. Estimates based on 30 years data are less precision in April, May, June, July, August and September in relation to the others.
\end{abstract}

Key words: time series, sampling, error estimation, confidence interval, inferential statistics.

IDepartamento de Fitotecnia, Centro de Ciências Rurais (CCR), Universidade Federal de Santa Maria (UFSM), 97105-900, Santa

Maria, RS, Brasil. E-mail: cargnelutti@pq.cnpq.br. Autor para correspondência.

IIFundação Estadual de Pesquisa Agropecuária (FEPAGRO), Porto Alegre, RS, Brasil. 


\section{INTRODUÇÃO}

A precipitação pluvial, a insolação, a radiação solar global e as temperaturas mínima, média e máxima são elementos meteorológicos importantes em trabalhos de zoneamento de culturas agrícolas, indicação de épocas de semeadura, irrigação, determinação de potencial de produtividade, zoneamento de riscos climáticos, crédito e seguro agrícola. Assim, é importante medir a disponibilidade desses elementos meteorológicos, com a máxima precisão possível, em um determinado local e período do ano, para o planejamento de atividades que minimizem riscos climáticos.

A média estimada a partir de um determinado número de observações (anos) tem sido uma medida comumente utilizada para medir a disponibilidade de elementos meteorológicos, e a World Meteorological Organization (WMO) preconiza que o número mínimo de anos de dados climáticos para a análise é de 30 anos. No entanto, a média, ausente de uma medida de variabilidade dos dados (amplitude, desvio padrão, variância e coeficiente de variação), é insuficiente para inferir sobre a confiabilidade de tais estimativas. Por outro lado, essas medidas de dispersão podem ocasionar problemas na interpretação. Por exemplo, o uso da amplitude pode não ser coerente, pelo fato de que a amostra pode não conter o maior e o menor valor populacional. No caso do coeficiente de variação, em dados em que a escala é de menos a mais infinito, seu valor poderá estar inflacionado.

A obtenção de todos os elementos de uma população finita possibilita calcular os parâmetros de uma variável, com ausência de erro. Em populações infinitas, a obtenção de todos os elementos é impossível. A disponibilidade de tempo, de mão-deobra, de dados e de recursos financeiros e humanos dificulta a coleta de todos os dados, sendo necessário estimar o parâmetro por meio de medições realizadas em um determinado número de elementos da população (amostra). Fica evidente que a estimativa obtida a partir de uma amostra está associada a um erro. No entanto, planos de amostragem são utilizados a fim de definir a amostra cuja estimativa seja a mais próxima possível do parâmetro. Conjuntos de dados com pouca variabilidade podem ser representados por uma amostra de tamanho menor, quando comparados a um grupo de dados heterogêneos.

Estudos de tamanho de amostra para a estimativa da temperatura máxima (CARGNELUTTI FILHO et al., 2006b) e mínima do ar média mensal (CARGNELUTTI FILHO et al., 2006a) e da radiação solar global média decendial (CARGNELUTTI FILHO et al., 2007), no Estado do Rio Grande do Sul, mostraram variabilidade do tamanho de amostra (número de anos) no tempo (meses e decêndios) e no espaço (locais). Maior tamanho de amostra, para a estimativa da temperatura máxima, é necessário nos meses de maio, junho, julho e agosto e, para a estimativa da temperatura mínima, é necessário nos meses de maio, junho e julho (CARGNELUTTI FILHO et al., 2006a; CARGNELUTTI FILHO et al., 2006b). Em relação à radiação solar global média decendial, CARGNELUTTI FILHO et al. (2007) concluíram que maior tamanho de amostra é necessário nos decêndios dos meses de junho, julho, agosto e setembro, em relação aos outros meses. Também concluíram que, para os locais e decêndios estudados, 30 anos de observações, são suficientes para estimar a média $(\mu)$ de radiação solar global média decendial, para um erro de estimação igual a $0,123 \hat{\mu}$, com coeficiente de confiança de $95 \%$.

Porém, estudos da precisão das estimativas das médias mensais de precipitação pluvial, insolação, radiação solar global e temperaturas mínima, média e máxima, obtidas com 30 anos de observações, são pouco conhecidos no Estado do Rio Grande do Sul. Assim, o objetivo deste trabalho foi estudar a variabilidade temporal e espacial da precisão das estimativas das médias mensais de precipitação pluvial, insolação, radiação solar global e temperaturas mínima, média e máxima, de 15 locais do Estado do Rio Grande do Sul.

\section{MATERIAL E MÉTODOS}

Foram utilizados os dados de precipitação pluvial, insolação, radiação solar global e temperaturas mínima, média e máxima, de 15 estações agrometeorológicas, oriundas de 15 locais (Caxias do Sul, Cruz Alta, Encruzilhada do Sul, Ijuí, Júlio de Castilhos, Maquiné, Rio Grande, Santa Maria, Santa Rosa, São Borja, São Gabriel, Taquari, Uruguaiana, Vacaria e Veranópolis) do Estado do Rio Grande do Sul (Tabela 1). Os dados foram obtidos do Banco de Dados do Centro de Meteorologia Aplicada da Fundação Estadual de Pesquisa Agropecuária - FEPAGRO/SCTRS e coletados no período de 1956 a 2007.

Em cada local e ano, foram calculadas a precipitação pluvial, em mm mês ${ }^{-1}$, e as médias mensais de insolação, em horas dia ${ }^{-1}$, de radiação solar global, em cal $\mathrm{cm}^{-2} \mathrm{dia}^{-1}$, e de temperaturas mínima, média e máxima, em ${ }^{\circ} \mathrm{C}$, de cada um dos 12 meses do ano.

Foram formadas 1080 séries temporais ( 15 locais x 12 meses x seis elementos meteorológicos), com número diferenciado de anos de observações em cada série, em função da disponibilidade de dados 
Variabilidade temporal e espacial da precisão das estimativas de elementos meteorológicos no Rio Grande do Sul.

Tabela 1 - Altitude, em metros, latitude e longitude, em graus, minutos e segundos, de 15 locais do Estado do Rio Grande do Sul.

\begin{tabular}{|c|c|c|c|}
\hline Local & Altitude (m) & Latitude (S) & Longitude (W) \\
\hline Caxias do Sul & 787 & $29^{\circ} 10^{\prime} 25^{\prime \prime}$ & $51^{\circ} 12^{\prime} 21^{\prime \prime}$ \\
\hline Cruz Alta & 473 & $28^{\circ} 38^{\prime} 21^{\prime \prime}$ & $53^{\circ} 36^{\prime} 34^{\prime \prime}$ \\
\hline Encruzilhada do Sul & 420 & $30^{\circ} 32^{\prime} 35^{\prime \prime}$ & $52^{\circ} 31^{\prime} 20^{\prime \prime}$ \\
\hline Ijuí & 448 & $28^{\circ} 23^{\prime} 17^{\prime}$ & $53^{\circ} 54^{\prime} 50^{\prime}$, \\
\hline Júlio de Castilhos & 514 & $29^{\circ} 13^{\prime} 26^{\prime \prime}$ & $53^{\circ} 40^{\prime} 45^{\prime}$, \\
\hline Maquiné & 32 & $29^{\circ} 40^{\prime} 49^{\prime \prime}$ & $50^{\circ} 13^{\prime} 56^{\prime \prime}$ \\
\hline Rio Grande & 15 & $32^{\circ} 01^{\prime} 44^{\prime \prime}$ & $52^{\circ} 15^{\prime} 37^{\prime \prime}$ \\
\hline Santa Maria & 95 & $29^{\circ} 41^{\prime} 25^{\prime \prime}$ & $53^{\circ} 48^{\prime} 42^{\prime}$, \\
\hline Santa Rosa & 273 & $27^{\circ} 51^{\prime} 50^{\prime \prime}$ & $54^{\circ} 29^{\prime} 03^{\prime \prime}$ \\
\hline São Borja & 99 & $28^{\circ} 39^{\prime} 44^{\prime \prime}$ & $56^{\circ} 00^{\prime} 15^{\prime \prime}$ \\
\hline São Gabriel & 109 & $30^{\circ} 27^{\prime} 27^{\prime \prime}$ & $54^{\circ} 19^{\prime} 01^{\prime \prime}$ \\
\hline Taquari & 76 & $29^{\circ} 48^{\prime} 15^{\prime \prime}$ & $51^{\circ} 49^{\prime} 30^{\prime \prime}$ \\
\hline Uruguaiana & 74 & $29^{\circ} 45^{\prime} 23^{\prime}$ & $57^{\circ} 05^{\prime} 12^{\prime}$ \\
\hline Vacaria & 955 & $28^{\circ} 30^{\prime} 09^{\prime \prime}$ & $50^{\circ} 56^{\prime} 12^{\prime}$ \\
\hline Veranópolis & 705 & $28^{\circ} 56^{\prime} 14^{\prime \prime}$ & $51^{\circ} 33^{\prime} 11^{\prime \prime}$ \\
\hline
\end{tabular}

meteorológicos. Para cada série temporal, foram estimados a média mensal ( $\hat{\mu})$ e o desvio padrão amostral (S), usando somente as últimas 30 observações do período de 1956 a 2007. A partir dessas estimativas, calculou-se o erro de estimação (semiamplitude do intervalo de confiança) (EE), em percentagem da estimativa da média mensal ( $\hat{\mu})$ de precipitação pluvial, insolação, radiação solar global e temperaturas mínima, média e máxima, para cada mês e local. Para isso, utilizou-se a expressão

$$
\text { erro de estimação }=\frac{t_{\alpha / 2} S}{\sqrt{n} \hat{\mu}} \times 100
$$

deduzida a partir de

$$
\text { erro padrão de estimação }=\mathrm{t}_{\alpha / 2} \mathrm{~S} / \sqrt{\mathrm{n}}
$$

(FONSECA \& MARTINS 1995; COSTA-NETO, 2002; BARBETTA et al., 2004; SPIEGEL et al., 2004), na qual $t_{\alpha / 2}$ é o valor da distribuição $t$ de Student, cuja área à direita é igual a $\alpha / 2$, isto é, é o valor de $t$, tal que: $\mathrm{P}(\mathrm{t}>$ $\left.t_{\alpha / 2}\right)=\alpha / 2$, com (n-1) graus de liberdade e $\alpha=5 \%$ de probabilidade de erro, e $n$ é o tamanho de amostra (fixado em 30 anos de observações - média histórica).

A partir da semiamplitude do intervalo de confiança, para cada um dos elementos meteorológicos, em cada mês e local do Estado do Rio Grande do Sul, determinaram-se as matrizes de distância euclidiana média padronizada entre os 12 meses e entre os 15 locais. Essas matrizes, em escala relativa, foram utilizadas como medida de dissimilaridade para a análise de agrupamento dos meses e dos locais, respectivamente, pelo método hierárquico de Ward (CRUZ \& REGAZZI, 1997; CRUZ, 2001). Em cada agrupamento, foi calculado o coeficiente de correlação linear de Pearson (r) entre a matriz de distância euclidiana média padronizada e a matriz gráfica e sua significância verificada pelo teste $\mathrm{t}$ de Student, a 1\% de probabilidade de erro. As análises foram realizadas com o auxílio da planilha eletrônica Office Excel e do programa Genes (CRUZ, 2001).

\section{RESULTADOS E DISCUSSÃO}

A semiamplitude do intervalo de confiança em percentagem da estimativa da média $(\hat{\mu})$ de precipitação pluvial mensal com coeficiente de confiança de $95 \%$, com base em uma amostra de 30 anos, oscilou de 11,95\% (mês de abril em Caxias do Sul) a 33,23\% (mês de maio em Ijuí) (Tabela 2). Portanto, pode-se inferir, com $95 \%$ de confiança, que, com o uso de 30 anos de observações, o erro máximo na estimativa da média $(\hat{\mu})$ de precipitação pluvial mensal será de $\pm 33,23 \%$ de $\mathrm{mm} \mathrm{mes}^{-1}$, independentemente do mês e local. Caso a estimativa da média $(\hat{\mu})$ de precipitação pluvial mensal, a partir de 30 anos, fosse $100 \mathrm{~mm} \mathrm{mes}^{-1}$, poder-se-ia inferir, com $95 \%$ de confiança, que a média $(\mu)$ de precipitação pluvial mensal estaria entre o limite inferior $66,77 \mathrm{~mm}(100-33,23)$ e o limite superior $133,23 \mathrm{~mm}(100+33,23)$ do intervalo de confiança.

De maneira geral, entre os elementos meteorológicos, com base em 30 anos de observações, menor precisão da estimativa (maior magnitude da semiamplitude do intervalo de confiança) da média $(\mu)$ de precipitação pluvial mensal (média $=21,66 \%$ ) foi observada em relação aos demais (Tabelas 2 e 3). Assim, pode-se inferir que a obtenção de estimativas desse elemento meteorológico com a mesma precisão dos 
Cargnelutti Filho et al.

Tabela 2 - Semiamplitude do intervalo de confiança em percentagem da estimativa das médias mensais de precipitação pluvial, em mm mês ${ }^{-1}$, de insolação, em horas dia ${ }^{-1}$, e de radiação solar global, em cal cm${ }^{-2}$ dia $^{-1}$, com base em 30 anos de observações, em cada mês e local do Estado do Rio Grande do Sul.

\begin{tabular}{|c|c|c|c|c|c|c|c|c|c|c|c|c|c|}
\hline Local & JAN & FEV & MAR & ABR & MAI & JUN & JUL & AGO & SET & OUT & NOV & DEZ & Média \\
\hline Caxias do Sul & 16,08 & 19,99 & 18,35 & 11,95 & 20,09 & 16,33 & 14,35 & 23,77 & 20,15 & 19,12 & 16,57 & 17,94 & 17,89 \\
\hline Cruz Alta & 20,70 & 24,93 & 18,45 & 24,83 & 25,61 & 15,25 & 21,94 & 21,17 & 19,36 & 21,29 & 23,98 & 24,88 & 21,87 \\
\hline Encruzilhada do Sul & 18,93 & 23,30 & 21,48 & 24,30 & 25,50 & 20,34 & 18,39 & 22,00 & 18,64 & 20,68 & 21,80 & 20,30 & 21,31 \\
\hline Ijuí & 20,88 & 23,74 & 17,75 & 22,36 & 33,23 & 22,45 & 21,32 & 23,12 & 16,44 & 19,99 & 23,38 & 21,64 & 22,19 \\
\hline Júlio de Castilhos & 18,89 & 20,30 & 20,02 & 19,82 & 25,87 & 19,23 & 20,39 & 22,52 & 18,12 & 20,57 & 23,93 & 22,61 & 21,02 \\
\hline Maquiné & 19,03 & 18,79 & 19,05 & 21,09 & 29,62 & 23,71 & 22,18 & 22,81 & 21,98 & 16,71 & 18,41 & 17,80 & 20,93 \\
\hline Rio Grande & 27,20 & 30,28 & 24,62 & 29,41 & 24,90 & 20,63 & 27,89 & 21,01 & 20,00 & 21,49 & 28,03 & 27,52 & 25,25 \\
\hline Santa Maria & 22,48 & 21,03 & 22,17 & 22,50 & 25,83 & 18,66 & 21,58 & 24,17 & 20,86 & 22,20 & 24,11 & 21,95 & 22,29 \\
\hline Santa Rosa & 19,48 & 23,21 & 20,74 & 24,05 & 25,93 & 17,87 & 25,52 & 25,14 & 12,51 & 19,16 & 21,39 & 25,94 & 21,74 \\
\hline São Borja & 25,91 & 22,58 & 20,81 & 21,74 & 26,14 & 26,70 & 22,30 & 23,62 & 16,26 & 22,33 & 22,88 & 19,29 & 22,55 \\
\hline São Gabriel & 22,39 & 28,97 & 25,21 & 25,43 & 24,83 & 19,68 & 21,55 & 23,68 & 19,21 & 22,86 & 23,66 & 27,06 & 23,71 \\
\hline Taquari & 19,49 & 19,70 & 14,66 & 23,54 & 24,10 & 16,78 & 17,67 & 19,21 & 17,96 & 20,61 & 18,16 & 20,92 & 19,40 \\
\hline Uruguaiana & 29,69 & 24,90 & 24,81 & 23,30 & 28,41 & 23,17 & 26,18 & 24,17 & 22,51 & 25,09 & 23,11 & 24,36 & 24,97 \\
\hline Vacaria & 15,97 & 16,95 & 21,31 & 23,69 & 24,20 & 18,08 & 23,54 & 21,59 & 19,33 & 19,70 & 19,12 & 21,94 & 20,45 \\
\hline Veranópolis & 15,63 & 19,78 & 15,48 & 21,06 & 23,93 & 17,81 & 19,21 & 21,06 & 19,60 & 17,84 & 19,21 & 20,73 & 19,28 \\
\hline Média & 20,85 & 22,56 & 20,33 & 22,60 & 25,88 & 19,78 & 21,60 & 22,60 & 18,86 & 20,64 & 21,85 & 22,33 & 21,66 \\
\hline Caxias do Sul & 7,78 & 6,37 & 6,81 & 8,22 & 8,12 & 8,55 & 6,75 & 9,16 & 8,88 & 7,17 & 6,75 & 10,63 & 7,93 \\
\hline Cruz Alta & 5,27 & 5,78 & 4,91 & 6,66 & 6,55 & 9,51 & 9,32 & 8,74 & 5,53 & 5,64 & 5,80 & 3,92 & 6,47 \\
\hline Encruzilhada do Sul & 7,16 & 8,06 & 6,25 & 9,22 & 7,51 & 8,41 & 7,94 & 8,92 & 7,34 & 8,77 & 6,81 & 6,90 & 7,77 \\
\hline Ijuí & 6,92 & 5,51 & 4,25 & 7,29 & 7,60 & 7,06 & 7,05 & 6,88 & 7,29 & 4,99 & 5,28 & 4,89 & 6,25 \\
\hline Júlio de Castilhos & 5,77 & 5,61 & 4,83 & 6,46 & 6,30 & 7,25 & 7,09 & 6,40 & 6,26 & 5,68 & 4,39 & 4,03 & 5,84 \\
\hline Maquiné & 6,05 & 7,37 & 6,02 & 5,65 & 6,57 & 5,67 & 8,42 & 8,55 & 7,50 & 7,39 & 6,81 & 3,72 & 6,64 \\
\hline Rio Grande & 5,84 & 6,69 & 5,74 & 7,52 & 7,13 & 8,85 & 8,88 & 7,91 & 6,57 & 7,46 & 5,89 & 4,01 & 6,87 \\
\hline Santa Maria & 8,95 & 8,25 & 7,38 & 8,72 & 9,38 & 9,43 & 10,63 & 9,99 & 7,83 & 7,05 & 6,14 & 7,31 & 8,42 \\
\hline Santa Rosa & 5,85 & 5,74 & 5,36 & 7,67 & 8,63 & 7,23 & 7,47 & 6,74 & 5,39 & 6,80 & 5,17 & 4,12 & 6,35 \\
\hline São Borja & 4,94 & 4,80 & 4,22 & 6,49 & 5,78 & 7,47 & 5,93 & 6,55 & 4,98 & 4,87 & 4,91 & 3,51 & 5,37 \\
\hline São Gabriel & 5,70 & 6,55 & 4,82 & 9,10 & 7,70 & 7,44 & 7,21 & 7,51 & 6,15 & 5,44 & 5,71 & 4,57 & 6,49 \\
\hline Taquari & 5,56 & 6,36 & 4,18 & 7,56 & 6,71 & 7,24 & 7,46 & 8,68 & 7,71 & 5,21 & 4,91 & 4,42 & 6,33 \\
\hline Uruguaian & 5,50 & 7,37 & 5,59 & 8,62 & 7,42 & 9,70 & 7,07 & 6,97 & 6,93 & 6,66 & 7,23 & 5,16 & 7,02 \\
\hline Vacaria & 6,95 & 8,66 & 6,00 & 8,35 & 7,47 & 6,63 & 7,23 & 6,67 & 6,28 & 7,06 & 5,45 & 5,19 & 6,83 \\
\hline Veranópolis & 7,45 & 5,98 & 5,24 & 7,21 & 6,88 & 7,09 & 6,61 & 7,41 & 6,48 & 6,18 & 5,23 & 5,60 & 6,45 \\
\hline Média & 6,38 & 6,61 & 5,44 & 7,65 & 7,32 & 7,83 & 7,67 & 7,80 & 6,74 & 6,43 & 5,77 & 5,20 & 6,74 \\
\hline & & & & & & -- radi & ăo sol & obal & & & & & . \\
\hline Caxias do Sul & 4,19 & 5,37 & 4,60 & 3,82 & 3,73 & 3,31 & 4,79 & 3,72 & 4,29 & 5,31 & 4,20 & 3,03 & 4,20 \\
\hline Cruz Alta & 5,64 & 6,29 & 5,48 & 5,80 & 5,02 & 6,99 & 6,39 & 5,08 & 5,85 & 6,21 & 5,36 & 5,13 & 5,77 \\
\hline Encruzilhada do Sul & 5,73 & 7,20 & 5,14 & 6,32 & 6,80 & 7,42 & 6,45 & 6,65 & 5,18 & 5,17 & 5,20 & 4,83 & 6,01 \\
\hline Ijuí & 5,80 & 5,89 & 5,26 & 7,74 & 6,30 & 6,38 & 6,47 & 5,37 & 7,23 & 5,59 & 6,00 & 4,25 & 6,02 \\
\hline Júlio de Castilhos & 8,61 & 8,23 & 8,66 & 6,43 & 8,89 & 8,87 & 8,62 & 9,06 & 8,39 & 6,91 & 6,81 & 7,57 & 8,09 \\
\hline Maquiné & 7,01 & 7,42 & 7,93 & 6,98 & 8,19 & 7,89 & 6,68 & 9,25 & 8,17 & 7,91 & 8,25 & 7,72 & 7,78 \\
\hline Rio Grande & 7,60 & 8,21 & 7,10 & 5,66 & 6,43 & 7,16 & 6,75 & 6,96 & 6,59 & 6,32 & 7,14 & 7,07 & 6,92 \\
\hline Santa Maria & 4,97 & 5,30 & 3,03 & 4,81 & 5,38 & 4,96 & 5,12 & 5,35 & 4,75 & 5,20 & 5,28 & 3,45 & 4,80 \\
\hline Santa Rosa & 3,71 & 4,39 & 5,89 & 4,09 & 6,03 & 6,87 & 9,21 & 7,01 & 6,31 & 4,61 & 5,28 & 3,82 & 5,60 \\
\hline São Borja & 5,03 & 5,89 & 5,28 & 5,55 & 5,17 & 5,59 & 5,09 & 5,29 & 5,62 & 4,29 & 4,74 & 5,06 & 5,22 \\
\hline São Gabriel & 3,22 & 4,15 & 4,20 & 5,23 & 5,39 & 4,73 & 4,93 & 4,64 & 4,20 & 5,06 & 4,47 & 3,25 & 4,46 \\
\hline Taquari & 3,45 & 3,51 & 3,79 & 3,64 & 3,93 & 3,84 & 4,71 & 5,04 & 4,84 & 3,37 & 3,69 & 2,82 & 3,89 \\
\hline Uruguaiana & 3,34 & 3,56 & 4,02 & 5,51 & 4,74 & 5,15 & 4,55 & 4,39 & 6,59 & 4,23 & 3,40 & 3,09 & 4,38 \\
\hline Vacaria & 3,42 & 3,90 & 4,14 & 4,62 & 4,55 & 4,39 & 5,02 & 3,90 & 3,59 & 5,18 & 3,07 & 4,61 & 4,20 \\
\hline Veranópolis & 5,04 & 4,82 & 4,42 & 4,83 & 5,28 & 5,92 & 7,93 & 6,26 & 5,72 & 5,99 & 5,44 & 4,36 & 5,50 \\
\hline Média & 5,12 & 5,61 & 5,26 & 5,40 & 5,72 & 5,96 & 6,18 & 5,86 & 5,82 & 5,42 & 5,22 & 4,67 & 5,52 \\
\hline
\end{tabular}


Variabilidade temporal e espacial da precisão das estimativas de elementos meteorológicos no Rio Grande do Sul.

Tabela 3 - Semiamplitude do intervalo de confiança em percentagem da estimativa das médias mensais de temperatura mínima, média e máxima, em ${ }^{\circ} \mathrm{C}$, com base em 30 anos de observações, em cada mês e local do Estado do Rio Grande do Sul.

\begin{tabular}{|c|c|c|c|c|c|c|c|c|c|c|c|c|c|}
\hline Local & JAN & FEV & MAR & ABR & MAI & JUN & JUL & AGO & SET & OUT & NOV & DEZ & Média \\
\hline & \multicolumn{13}{|c|}{------------------------------------------------------ temperatura mínima ---------------------------------------------------- } \\
\hline Caxias do Sul & 2,24 & 2,39 & 2,56 & 4,38 & 5,92 & 6,59 & 8,04 & 6,18 & 4,52 & 4,70 & 3,28 & 2,77 & 4,46 \\
\hline Cruz Alta & 2,10 & 1,94 & 2,50 & 4,13 & 5,66 & 6,29 & 7,48 & 5,35 & 4,19 & 4,11 & 2,85 & 2,53 & 4,09 \\
\hline Encruzilhada do Sul & 2,22 & 2,21 & 2,60 & 3,73 & 6,43 & 6,16 & 7,83 & 5,23 & 5,00 & 4,49 & 3,18 & 2,60 & 4,31 \\
\hline Ijuí & 2,08 & 2,25 & 2,89 & 4,33 & 6,06 & 6,95 & 8,72 & 5,63 & 4,63 & 4,27 & 2,89 & 2,47 & 4,43 \\
\hline Júlio de Castilhos & 2,68 & 2,39 & 2,52 & 3,93 & 5,54 & 6,63 & 7,66 & 5,88 & 4,41 & 4,59 & 3,51 & 2,83 & 4,38 \\
\hline Maquiné & 2,64 & 3,12 & 3,25 & 4,20 & 5,83 & 6,76 & 7,66 & 5,73 & 4,85 & 4,82 & 2,84 & 2,60 & 4,52 \\
\hline Rio Grande & 2,04 & 2,17 & 2,40 & 3,03 & 5,19 & 6,27 & 6,26 & 4,47 & 3,64 & 3,76 & 2,23 & 1,98 & 3,62 \\
\hline Santa Maria & 1,96 & 2,16 & 2,28 & 3,97 & 5,85 & 7,15 & 7,45 & 5,18 & 4,21 & 4,23 & 3,35 & 2,33 & 4,18 \\
\hline Santa Rosa & 2,40 & 2,00 & 2,49 & 4,65 & 6,39 & 6,81 & 7,53 & 5,65 & 4,54 & 4,29 & 3,46 & 2,52 & 4,39 \\
\hline São Borja & 1,84 & 1,78 & 2,67 & 4,01 & 5,80 & 7,31 & 7,37 & 5,27 & 4,19 & 4,47 & 2,98 & 2,56 & 4,19 \\
\hline São Gabriel & 2,38 & 2,66 & 3,06 & 4,82 & 6,88 & 8,56 & 8,42 & 6,57 & 4,93 & 4,81 & 3,72 & 2,79 & 4,97 \\
\hline Taquari & 1,80 & 1,99 & 2,31 & 3,82 & 5,88 & 6,59 & 7,17 & 5,18 & 3,93 & 3,59 & 2,70 & 2,23 & 3,93 \\
\hline Uruguaiana & 1,73 & 2,11 & 2,43 & 3,30 & 5,38 & 7,12 & 7,89 & 4,94 & 4,02 & 3,97 & 2,58 & 2,05 & 3,96 \\
\hline Vacaria & 2,71 & 3,08 & 3,23 & 5,71 & 8,94 & 9,70 & 12,41 & 8,28 & 5,29 & 5,07 & 3,88 & 3,30 & 5,97 \\
\hline Veranópolis & 2,26 & 2,66 & 2,48 & 4,62 & 6,29 & 7,30 & 8,23 & 6,11 & 5,50 & 4,55 & 2,87 & 2,55 & 4,62 \\
\hline Média & 2,20 & 2,33 & 2,65 & 4,18 & 6,13 & 7,08 & 8,01 & 5,71 & 4,52 & 4,38 & 3,09 & 2,54 & 4,40 \\
\hline & & & & & & 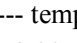 & eratur & . & & & & & ---- \\
\hline Caxias do Sul & 1,30 & 1,70 & 1,86 & 2,76 & 3,90 & 3,90 & 4,94 & 3,93 & 3,04 & 2,95 & 2,13 & 1,66 & 2,84 \\
\hline Cruz Alta & 1,20 & 1,41 & 1,76 & 2,38 & 3,52 & 3,73 & 4,62 & 3,41 & 2,91 & 2,49 & 1,83 & 1,65 & 2,58 \\
\hline Encruzilhada do Sul & 1,33 & 1,69 & 1,99 & 2,50 & 3,66 & 3,88 & 4,73 & 3,55 & 3,06 & 2,73 & 2,04 & 1,81 & 2,75 \\
\hline Ijuí & 1,25 & 1,41 & 1,84 & 2,39 & 3,55 & 3,86 & 4,73 & 3,10 & 2,78 & 2,36 & 1,68 & 1,61 & 2,55 \\
\hline Júlio de Castilhos & 1,36 & 1,45 & 1,79 & 2,57 & 3,50 & 3,78 & 4,68 & 3,71 & 2,82 & 2,59 & 1,91 & 1,93 & 2,67 \\
\hline Maquiné & 1,39 & 1,68 & 1,74 & 2,36 & 3,31 & 3,51 & 4,20 & 3,09 & 2,75 & 2,57 & 1,68 & 1,53 & 2,48 \\
\hline Rio Grande & 1,27 & 1,42 & 1,67 & 2,14 & 3,36 & 3,74 & 4,00 & 2,90 & 2,35 & 3,24 & 1,59 & 1,41 & 2,42 \\
\hline Santa Maria & 1,20 & 1,37 & 1,66 & 2,31 & 3,79 & 4,25 & 4,64 & 3,27 & 2,74 & 1,76 & 1,88 & 1,51 & 2,53 \\
\hline Santa Rosa & 1,35 & 1,42 & 1,66 & 2,40 & 3,56 & 3,68 & 4,36 & 3,26 & 2,74 & 2,27 & 1,82 & 1,39 & 2,49 \\
\hline São Borja & 1,37 & 1,50 & 1,84 & 2,17 & 3,53 & 4,11 & 4,33 & 3,41 & 2,69 & 2,48 & 1,96 & 1,82 & 2,60 \\
\hline São Gabriel & 1,30 & 1,55 & 1,98 & 2,44 & 3,90 & 4,28 & 4,56 & 3,41 & 2,73 & 2,51 & 2,01 & 1,69 & 2,70 \\
\hline Taquari & 1,20 & 1,51 & 1,59 & 2,23 & 3,64 & 3,80 & 4,38 & 3,08 & 2,59 & 2,32 & 1,72 & 1,43 & 2,46 \\
\hline Uruguaiana & 1,45 & 1,82 & 1,80 & 2,01 & 3,50 & 4,13 & 4,85 & 3,14 & 2,49 & 2,25 & 1,80 & 1,62 & 2,57 \\
\hline Vacaria & 1,42 & 1,74 & 2,07 & 2,88 & 4,27 & 4,37 & 5,62 & 4,04 & 3,12 & 2,80 & 1,94 & 1,86 & 3,01 \\
\hline Veranópolis & 1,19 & 1,78 & 1,88 & 2,86 & 3,92 & 4,03 & 4,95 & 3,77 & 3,18 & 2,90 & 1,91 & 1,55 & 2,83 \\
\hline Média & 1,31 & 1,56 & 1,81 & 2,43 & 3,66 & 3,94 & 4,64 & 3,40 & 2,80 & 2,55 & 1,86 & 1,63 & 2,63 \\
\hline Caxias do Sul & 1,27 & 1,67 & 1,74 & 2,24 & 3,16 & 2,93 & $\begin{array}{c}\text { ratura n } \\
3,76\end{array}$ & 3,28 & 2,71 & 2,31 & 1,97 & 1,69 & 2,--- \\
\hline Cruz Alta & 1,43 & 1,61 & 1,62 & 1,95 & 2,83 & 2,96 & 3,67 & 3,06 & 2,61 & 1,93 & 1,69 & 1,61 & 2,25 \\
\hline Encruzilhada do Sul & 1,46 & 1,83 & 2,02 & 2,18 & 3,02 & 3,07 & 3,59 & 3,11 & 2,57 & 2,15 & 1,80 & 1,76 & 2,38 \\
\hline Ijuí & 1,74 & 1,66 & 1,69 & 2,00 & 2,73 & 2,91 & 3,50 & 2,90 & 2,41 & 1,80 & 1,62 & 1,69 & 2,22 \\
\hline Júlio de Castilhos & 1,43 & 1,56 & 1,75 & 2,36 & 2,82 & 2,93 & 3,72 & 3,35 & 2,68 & 1,91 & 1,63 & 1,99 & 2,34 \\
\hline Maquiné & 1,30 & 1,39 & 1,37 & 1,99 & 2,55 & 2,59 & 3,23 & 2,77 & 2,36 & 1,80 & 1,55 & 1,40 & 2,03 \\
\hline Rio Grande & 1,24 & 1,28 & 1,52 & 1,98 & 2,59 & 2,65 & 2,94 & 2,47 & 2,16 & 3,20 & 1,62 & 1,48 & 2,09 \\
\hline Santa Maria & 1,47 & 1,60 & 1,70 & 1,87 & 3,02 & 3,55 & 3,54 & 3,00 & 2,36 & 1,68 & 1,68 & 1,61 & 2,26 \\
\hline Santa Rosa & 1,57 & 1,79 & 1,79 & 1,86 & 2,62 & 2,87 & 3,42 & 2,95 & 2,48 & 1,74 & 1,78 & 1,57 & 2,20 \\
\hline São Borja & 1,72 & 1,87 & 1,81 & 1,94 & 2,70 & 2,92 & 3,28 & 3,00 & 2,35 & 1,88 & 1,86 & 1,88 & 2,27 \\
\hline São Gabriel & 1,50 & 1,72 & 1,72 & 1,96 & 3,03 & 2,98 & 3,39 & 2,69 & 2,29 & 1,78 & 1,71 & 1,71 & 2,21 \\
\hline Taquari & 1,53 & 1,75 & 1,52 & 2,00 & 2,97 & 2,87 & 3,43 & 2,91 & 2,53 & 2,02 & 1,71 & 1,71 & 2,24 \\
\hline Uruguaiana & 1,77 & 2,06 & 1,74 & 2,03 & 2,88 & 3,22 & 3,87 & 2,88 & 2,21 & 1,81 & 1,74 & 1,76 & 2,33 \\
\hline Vacaria & 1,49 & 1,61 & 1,92 & 2,37 & 3,10 & 3,14 & 3,87 & 3,29 & 2,84 & 2,45 & 1,74 & 1,95 & 2,48 \\
\hline Veranópolis & 1,31 & 1,75 & 1,87 & 2,33 & 3,16 & 3,02 & 3,84 & 3,21 & 2,82 & 2,40 & 1,91 & 1,51 & 2,43 \\
\hline Média & 1,48 & 1,68 & 1,72 & 2,07 & 2,88 & 2,97 & 3,54 & 2,99 & 2,49 & 2,06 & 1,73 & 1,69 & 2,27 \\
\hline
\end{tabular}


demais é obtida com maior número de anos. Entre os elementos meteorológicos, a precisão, média de meses e locais, aumenta na seguinte ordem: precipitação pluvial $(21,66 \%)$, insolação $(6,74 \%)$, radiação solar global $(5,52 \%)$ e temperaturas mínima (4,40\%), média $(2,63 \%)$ e máxima $(2,27 \%)$ (Tabelas 2 e 3 ). Em relação à radiação solar global média decendial, CARGNELUTTI FILHO et al. (2007) encontraram valor máximo do erro de estimação, entre os locais e decêndios, de 12,3\% e valor médio de $7,1 \%$. Esse maior valor $(7,1 \%)$ em relação ao encontrado $(5,52 \%)$ é, provavelmente, explicado pela maior variabilidade esperada em escala decendial.

Os resultados revelam que há variabilidade da precisão das estimativas dos elementos meteorológicos com base em 30 anos de observações. Assim, pode-se inferir que estimativas com a mesma precisão seriam obtidas com o aumento progressivo do tamanho de amostra (número de anos), na seguinte ordem: temperatura máxima, média e mínima, radiação solar global, insolação e precipitação pluvial.

Os coeficientes de correlação linear de Pearson (r) entre a matriz de distância euclidiana média padronizada e a matriz gráfica foram significativos $(\mathrm{P} \leq 0,01)$ e com magnitude que oscilou entre 0,51 (agrupamento de meses em relação à precipitação pluvial) e 0,83 (agrupamento de meses em relação à temperatura máxima) (Figuras 1 e 2), revelando, respectivamente, menor e maior consistência do agrupamento.

Em um dendrograma, grande mudança de nível na distância de agrupamento indica a união de meses heterogêneos, podendo ser utilizada como critério para definição dos grupos (BARROSO \& ARTES, 2003). Assim, utilizando-se 70\% de similaridade como critério para definição dos grupos, pelo método de Ward, houve formação de três grupos de meses em relação à precipitação pluvial, insolação e radiação solar global. Em relação às temperaturas mínima, média e máxima, os três grupos foram obtidos a partir de $40 \%$ de similaridade (Figura 1). De maneira geral, com exceção da precipitação pluvial, a precisão das estimativas de insolação, radiação solar global e temperaturas mínima, média e máxima foi menor (maior magnitude da semi-amplitude do intervalo de confiança), nos meses centrais do ano (abril, maio, junho, julho, agosto e setembro), com aumento gradativo em direção à janeiro e dezembro. Esses resultados permitem inferir presença de variabilidade temporal (meses) da precisão dessas estimativas e aumento gradativo da precisão dos meses centrais em direção aos meses iniciais e finais. Esses resultados corroboram os trabalhos de CARGNELUTTI FILHO et al. (2006a, 2006b, 2007), que, de maneira geral, revelaram ser necessário maior tamanho de amostra para a estimativa da temperatura máxima e mínima do ar média mensal e da radiação solar global média decendial, no Estado do Rio Grande do Sul, nos meses e decêndios centrais do ano.

Houve formação de três grupos de locais, pelo método de Ward, em relação à precipitação pluvial, insolação, radiação solar global e temperaturas mínima, média e máxima, com $70 \%$ de similaridade (Figura 2). De maneira geral, esses três grupos separam locais com alta precisão das estimativas (menores magnitudes da semiamplitude do intervalo de confiança), média precisão e baixa precisão (maiores magnitudes da semiamplitude do intervalo de confiança). No entanto, de maneira geral, não há tendências de um determinado local estar totalmente relacionado com um determinado grupo de precisão. Como exemplo, o local 1 (Caxias do Sul) está no grupo de alta precisão em relação à precipitação pluvial e à radiação solar global, de média precisão quanto à temperatura mínima e baixa precisão quanto à insolação e às temperaturas média e máxima. Esses resultados permitem inferir presença de variabilidade espacial (locais) da precisão dessas estimativas.

Em conformidade com o exposto anteriormente, o pesquisador, ao utilizar estimativas de médias mensais de precipitação pluvial, insolação, radiação solar global e temperaturas mínima, média e máxima, deve considerar que há variabilidade da precisão das estimativas dos elementos meteorológicos com base em 30 anos de observações e que decisões tomadas a partir dessas informações são menos ou mais confiáveis, dependendo do elemento meteorológico, mês e local.

\section{CONCLUSÕES}

A precisão das estimativas entre os elementos meteorológicos aumenta na seguinte ordem: precipitação pluvial, insolação, radiação solar global e temperaturas mínima, média e máxima. Há variabilidade da precisão das estimativas das médias mensais de precipitação pluvial, insolação, radiação solar global e 
Variabilidade temporal e espacial da precisão das estimativas de elementos meteorológicos no Rio Grande do Sul.

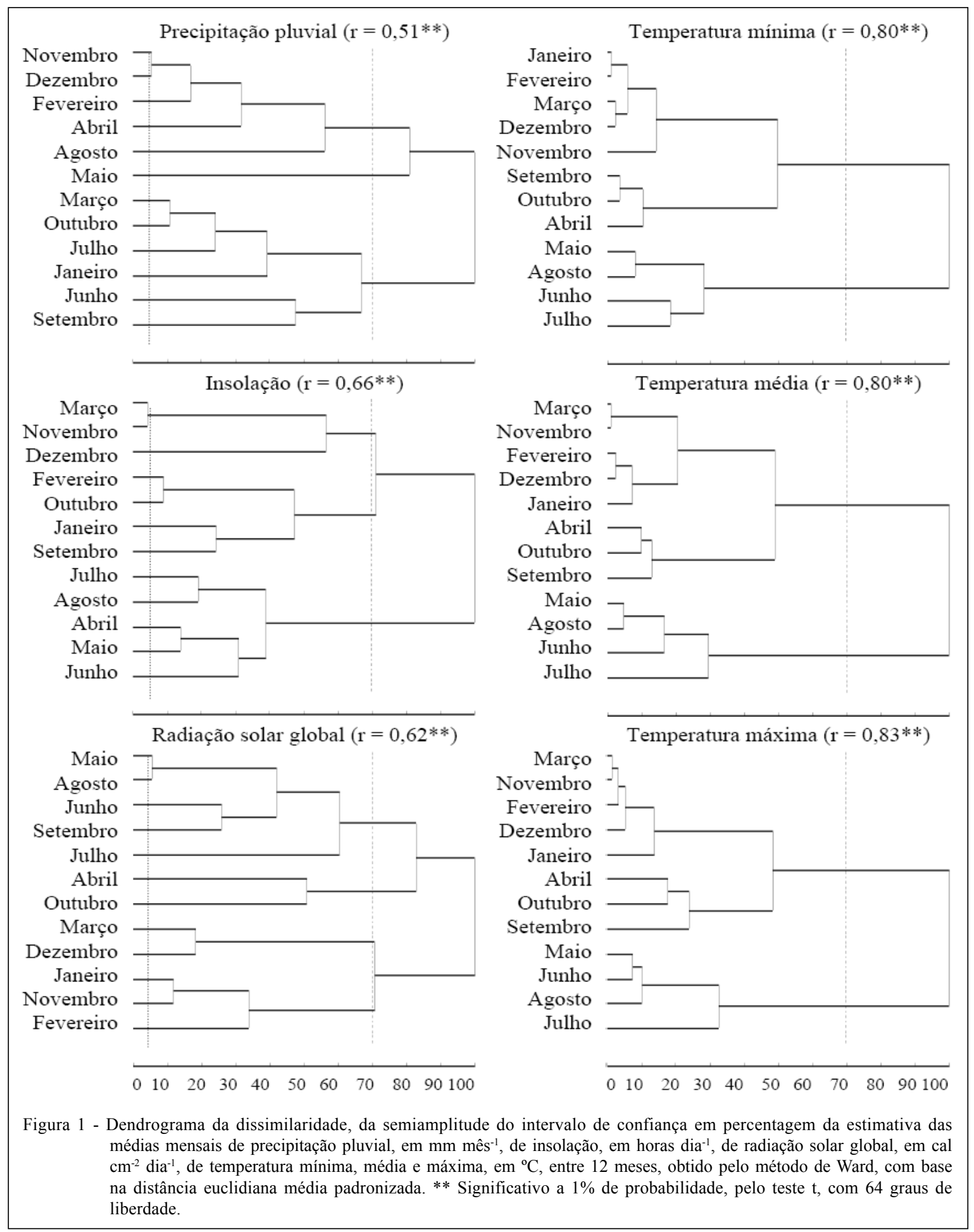

temperaturas mínima, média e máxima, no Estado do Rio Grande do Sul, no tempo (meses) e no espaço (locais). Estimativas com base em 30 anos de observações têm precisão menor nos meses de abril, maio, junho, julho, agosto e setembro, em relação aos demais meses.

\section{AGRADECIMENTOS}

Aos pesquisadores, aos técnicos, aos observadores meteorológicos, aos estagiários e às demais pessoas que, de alguma forma, contribuíram para a realização deste trabalho. Ao Conselho Nacional de Desenvolvimento Científico e Tecnológico (CNPq), pela concessão de bolsa de produtividade em pesquisa para Alberto Cargnelutti Filho. 
Cargnelutti Filho et al.

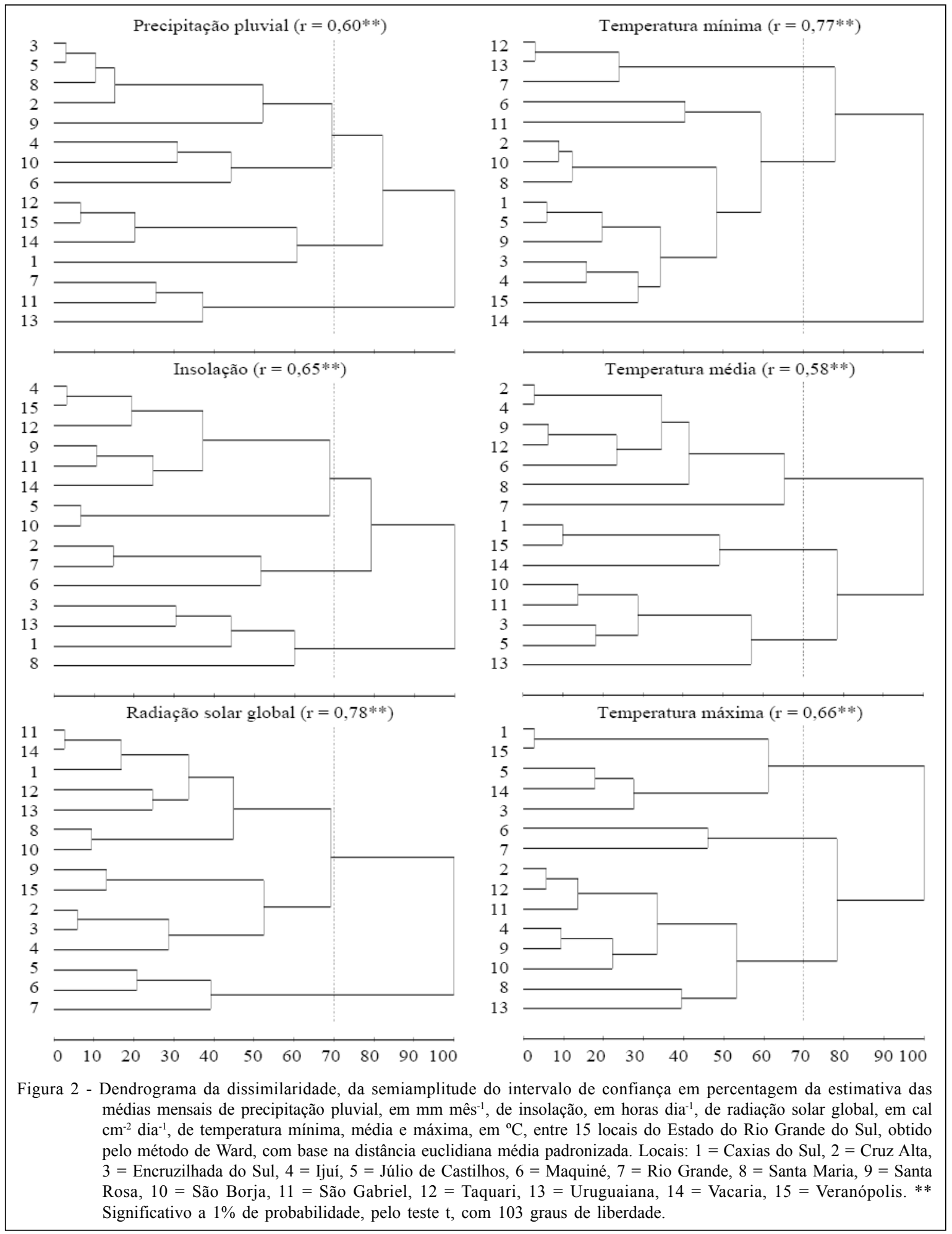

\section{REFERÊNCIAS}

BARBETTA, P.A. et al. Estatística para cursos de engenharia e informática. São Paulo: Atlas, 2004. 410p.

BARROSO, L.P.; ARTES, R. Análise multivariada. Lavras: UFLA, 2003. 151p.
CARGNELUTTI FILHO, A. et al. Tamanho de amostra para a estimativa das médias decendiais de radiação solar global no estado do Rio Grande do Sul. Ciência e Agrotecnologia, v.31, p.1402-1410, 2007. Disponível em: $<$ http://www.scielo.br/ scie lo.php?script=sci_arttext\&pid=S 1413 - 
$70542007000500020 \& \operatorname{lng}=$ pt\&nrm $=$ iso $>$. Doi: $10.1590 /$ S1413-70542007000500020.

CARGNELUTTI FILHO, A. et al. Variabilidade temporal e espacial do tamanho de amostra da temperatura mínima do ar no Rio Grande do Sul, Brasil. Ciência Rural, v.36, p.11561163, 2006a. Disponível em: <http://www.scielo.br/ s c i e lo.ph p s c ri pt $=$ s ci art text \& pid = S 0103 $84782006000400018 \& \operatorname{lng}=$ pt $\&$ nrm=iso $>$. Doi: $10.1590 /$ S0103-84782006000400018.

CARGNELUTTI FILHO, A. et al. Variabilidade temporal e espacial do tamanho de amostra para estimativa das médias mensais de temperatura máxima do ar no Estado do Rio Grande do Sul. Revista Brasileira de Agrometeorologia, v. 14, p.87-95, 2006b.
COSTA-NETO, P.L.O. Estatística. 2.ed. São Paulo: Edgard Blücher, 2002. 266p.

CRUZ, C.D. PROGRAMA GENES: versão Windows: aplicativo computacional em genética e estatística. Viçosa: UFV, 2001. 648p.

CRUZ, C.D.; REGAZZI, A.J. Modelos biométricos aplicados ao melhoramento genético. 2.ed. Viçosa: UFV, 1997. 390p.

FONSECA, J.S.; MARTINS, G.A. Curso de estatística. 5.ed. São Paulo: Atlas, 1995. 317p.

SPIEGEL, R.A. et al. Probabilidade e estatística. 2.ed. Porto Alegre: Bookman, 2004. 398p. 